\title{
METAMORFOSES: DESLOCAMENTO E PERTENCIMENTO EM "TUDO SÃO HISTÓRIAS DE AMOR", DE DULCE MARIA CARDOSO
}

\section{METAMORPHOSES: DISPLACEMENT AND BELONGING IN "TUDO SÃO HISTÓRIAS DE AMOR", BY DULCE MARIA CARDOSO}

\author{
Larissa Fonseca e Silva ${ }^{1}$ \\ ORCID: https://orcid.org/0000-0003-4501-9293
}

\begin{abstract}
Resumo: Neste artigo, propõe-se uma leitura do conto "Tudo são histórias de amor", da autora portuguesa Dulce Maria Cardoso, a partir de suas múltiplas camadas textuais, entendendo-as como partes do processo de (re)construção do sujeito que narra. A narradora, que se apresenta como Jinja, uma ex-cadela de rua, diz ter "entrado na cabeça" de Dulce quando esta escrevia um texto sobre Lisboa, o "Metamorfoses". Jinja e Dulce, dividindo a voz, também se identificam à própria Dulce Maria Cardoso, que se insere no texto a partir de índices autobiográficos referentes à sua vivência do exílio, tendo sido "retornada". A narradora, então, sendo aqui descrita como um sujeito fragmentado, deslocado e descentralizado (HUTCHEON, 1991; SAID, 2004; HALL, 2006), usa de diversas estratégias literárias para escrever sobre as "dimensões simultâneas" (SAID, 2003, p. 59) que experencia ao mesmo tempo em que passa a pertencer a Lisboa.
\end{abstract}

Palavras-chave: Dulce Maria Cardoso; retornados; deslocamento; pertencimento; pósmoderno.

\begin{abstract}
In this article, is proposed a reading of the short story "Tudo são histórias de amor", by the Portuguese author Dulce Maria Cardoso, based on its multiple textual layers, understanding them as part of the process of (re)construction of the subject who narrates. The narrator, who introduces herself as Jinja, an ex stray dog, says she "got into Dulce's head" when she was writing a text about Lisbon, "Metamorfoses". Jinja and Dulce, sharing the voice, also identify themselves with Dulce Maria Cardoso, who inserts herself into the text with autobiographical indices referring to her exile experience, having been "retornada".

\footnotetext{
${ }^{1}$ Mestranda em Teoria Literária e Crítica da Cultura (Linha de Pesquisa LMC - Literatura e Memória Cultural) no PROMEL (Programa de Mestrado em Letras da UFSJ), desenvolvendo o projeto de dissertação "Os ponteiros que nos situam: memória, tédio e identidade no romance Campo de Sangue, de Dulce Maria Cardoso", com o apoio da Fapemig. Licenciada em Letras - Língua Portuguesa e suas Literaturas pela UFSJ (Universidade Federal de São João del-Rei) e graduanda em Letras - Língua Inglesa e suas Literaturas também pela UFSJ. E-mail para contato: larissafonsil@yahoo.com.br
}

Lattes: http://lattes.cnpq.br/3130055055784468 
L. F. Silva Metamorfoses: deslocamento e pertencimento em "Tudo são histórias de amor", de Dulce Maria Cardoso

The narrator, then, being described here as a fragmented, displaced, and decentralized subject (HUTCHEON, 1991; SAID, 2004; HALL, 2006), uses several literary strategies to write about the "simultaneous dimensions" (SAID, 2003, p. 59) that she experiences in the process of belonging to Lisbon.

Key-words: Dulce Maria Cardoso; retornados; displacement; belonging; post-modern.

\section{Introdução:}

“[...] Ter sido uma cadela e conseguir escrever depois de morta não só parece estranho como é verdadeiramente estranho. A realidade é muitas vezes mais improvável do que a mais improvável das ficções" (CARDOSO, 2017, p. 112).

A cadela em questão, Jinja, teria entrado na cabeça da narradora de "Tudo são histórias de amor" (conto da coletânea homônima publicada, no Brasil, em 2017) quando esta escrevia um texto sobre Lisboa. Não por acaso, essa narradora se identifica também, e como será demonstrado ao longo deste artigo, com Dulce Maria Cardoso, a autora.

Uma das vencedoras do prêmio Oceanos de 2019, Dulce Cardoso já vinha se consolidando na literatura portuguesa desde o começo dos anos 2000. Em 2012, com a publicação de $O$ Retorno, livro em que ficcionaliza, por meio do personagem Rui, a experiência de ser "retornada", passa a ser vista como uma voz importante também dentro dessa literatura, a dos "retornados”.

"Retornados" é a denominação que se dava aos portugueses e filhos de portugueses que residiam em África e que precisaram, por ocasião das Guerras de Libertação nos anos 1970, voltar ${ }^{2}$ a Portugal, fugindo da retaliação dos revolucionários. A maioria precisou, inclusive, deixar no outro continente quase todos os seus bens. Os retornados, então, se por um lado eram refugiados, por outro eram assim chamados depreciativamente, posto que também eram vistos como exploradores dos nativos africanos e como ameaça ao sistema econômico-social de Portugal, frágil àquela época. Retornavam, afinal, aos milhares.

\footnotetext{
${ }^{2} \mathrm{O}$ termo "retornado" se aplicava a todos que vinham das ex-colônias portuguesas em África por ocasião das Guerras de Libertação, mas é válido reforçar que alguns dos retornados nunca haviam pisado em Portugal, já tendo nascido em solo africano. Dulce Maria Cardoso nasceu em Portugal, mas foi, ainda bebê, para Angola com a família. Ela retorna para Portugal aos onze anos de idade.
} 
L. F. Silva Metamorfoses: deslocamento e pertencimento em "Tudo são histórias de amor", de Dulce Maria Cardoso

O "ser retornado" era e é, de fato, uma experiência ambígua, como são as inúmeras experiências possíveis do sujeito pós-moderno ${ }^{3}$ que é, também, exilado. Segundo Edward Said em "Reflexões sobre o exílio":

[...] A maioria das pessoas tem consciência de uma cultura, um cenário, um país; os exilados têm consciência de pelo menos dois desses aspectos, e essa pluralidade de visão dá origem a uma consciência de dimensões simultâneas, uma consciência que para tomar emprestada uma palavra da música - é contrapontística (SAID, 2003, p. 59, grifo do autor).

A maior parte dos portugueses que residiam em território africano antes "do retorno" tinha ido para lá em busca de melhores condições de vida, sendo que muitos deles beiravam a miséria. A ditadura salazarista, por seu turno, incentivava a maior presença portuguesa naquilo que se convencionou chamar de "províncias ultramarinas" em África, as então colônias Angola, Moçambique, Cabo Verde, São Tomé e Príncipe e Guiné-Bissau. Dessa maneira, essas pessoas que, em Portugal, estavam às margens da população, e já sendo Portugal um país periférico dentro da Europa, tornaram-se colonas - ou "Prósperos Calibanizados", que é como Boaventura Santos (2003) descreve os colonos portugueses em "Entre Próspero e Caliban - colonialismo, pós-colonialismo e interidentidade":

$\mathrm{Na}$ ausência de critérios puros e peremptórios e de razões exterminadoras, o colonizador português não pôde apresentar um opulento menu de identidades imperiais. Nem identidade emancipadora nem identidade emancipada, oscilou entre Próspero e Caliban como que em busca da terceira margem do rio de que fala Guimarães Rosa. Nessas condições não foi possível consolidar essencialismos, os quais, sempre que nomeados, foram-no apenas para serem contestados, revelando assim sua intrínseca contingência. As colônias ora foram colônias, ora províncias ultramarinas; a miscigenação foi vista ora como degradação da raça, ora como a sua mais exaltante característica; e os povos nativos ora foram selvagens, ora cidadãos nacionais (SANTOS, 2003, p. 50).

Calibanizado ou não, violência, segregacionismo, abusos e racismo contra os nativos africanos existiram, como em qualquer processo colonial e como bem denunciam vários autores contemporâneos que viveram em África antes da descolonização. Generalizar ou

\footnotetext{
${ }^{3} \mathrm{O}$ conceito, aqui, é usado em consonância com Stuart Hall (2006) em A identidade cultural na pósmodernidade. Para Hall, o sujeito pós-moderno não tem uma identidade fixa ou essencial, mas identidades cambiáveis, muitas das quais surgem junto aos movimentos sociais que emergem nos anos 60 .
} 
L. F. Silva Metamorfoses: deslocamento e pertencimento em "Tudo são histórias de amor", de Dulce Maria Cardoso

“essencializar", porém, demonizando todos os ex-colonos, ignorando contextos históricos e desconsiderando quem, de fato, detinha o poder e sustentava a colonização, é sempre um risco de incorrer em injustiças. Como um paralelo, foi dentre os próprios soldados portugueses que eram enviados à África para combater os guerrilheiros, por exemplo, que partiu a Revolução dos Cravos em 1974 - e esta, com a queda da ditadura portuguesa, acelerou o processo de emancipação das colônias. Em suma, como aponta Isabela Figueiredo, também escritora retornada, em seu Caderno de memórias coloniais, “A verdade era uma história muito longa e complexa, rica de narrativas encaixadas alternadas, simultâneas, polifónica"” (FIGUEIREDO, 2018, p. 150):

Todos os lados possuem uma verdade indesmentível. Nada a fazer. Presos na sua certeza absoluta, nenhum admitirá a mentira que edificou para caminhar sem culpa, para conseguir dormir, acordar, comer, trabalhar. Para continuar. Há inocentes-inocentes e inocentes-culpados. Há tantas vítimas entre os inocentes-inocentes como entre os inocentes-culpados. Há vítimas-vítimas e vítimas-culpadas. Entre as vítimas há carrascos (FIGUEIREDO, 2018, p. 136).

Eliana Tolentino, no artigo "Retorno e retornados - um não lugar, um não estar", em que faz uma leitura dos livros Cadernos de memórias coloniais e $O$ Retorno pensando o sujeito retornado em Portugal, escreve sobre os escritores retornados:

Essa nova geração de portugueses aponta para a consciência do papel da colonização. Em várias áreas, essa geração de herdeiros de uma memória que os faz se envergonhar de seu país vem escrevendo sobre os de lá, os de cá e os que de lá voltaram após a "descolonização." O pós-74 resultou numa produção literária significativa e para Eduardo Lourenço era Como se nesse momento, quer dizer, depois de 75 , entre 75 e 80, em Portugal, a consciência portuguesa, a imaginação portuguesa, o imaginário português quisessem desenhar um outro mapa. (LOURENÇO, 2004, p. 349) (TOLENTINO, 2017, p. 6051).

E complementa:

\footnotetext{
${ }^{4}$ Neste artigo, foram mantidas a ortografia e pontuação dos textos dos autores portugueses.
} 
L. F. Silva Metamorfoses: deslocamento e pertencimento em "Tudo são histórias de amor", de Dulce Maria Cardoso

Essa literatura pós-25 de abril, portanto, presta-se a um ajuste de contas de um sujeito expatriado, confronta a comunidade imaginada, o Outro e a diferença. Nesse sentido, as articulações das diferenças, dos retornados, das memórias criadas e herdadas devem ser lidas a partir dessa presença do Outro. Mas não se pode deixar de olhar também que essa é uma via de mão dupla e a colonização bem como a descolonização rearranjam as nações (TOLENTINO, 2017, p. 6052).

Com tudo isso, e voltando ao "Tudo são histórias de amor", percebe-se o porquê de Dulce Maria Cardoso, ocupando um lugar de retornada, escrever um conto com diversos fragmentos dos mais diversos discursos e com uma narradora marcada pela multiplicidade escrevendo, por seu turno, sobre Lisboa, capital de Portugal. Pluralidade histórica, dialogismo e hibridismo, como aponta Linda Hutcheon em "Descentralizando o pósmoderno: o ex-cêntrico" (capítulo de Poética do pós-modernismo), são caraterísticos das narrativas pós-modernas. Como observa Edward Said, os exilados têm “'[...] necessidade [...] de reconstruir uma identidade a partir de refrações e descontinuidades" (SAID, 2003, p. 52).

Assim, a narradora de "Tudo são histórias de amor", para escrever sobre Lisboa, recorre a discursos históricos acerca do terremoto de 1755; recorre ao mito da fundação da cidade por Ulisses; recorre às lembranças ficcionais de uma personagem lisboana que, vendo-se abandonada pelo marido, se identifica tanto com Penélope quanto com Ophiusa que, por sua vez, na ficção de Cardoso, guarda grandes semelhanças com Circe e Calipso da Odisseia de Homero.

A narradora recorre, ainda, à própria voz como autora Dulce Maria Cardoso, em uma narrativa que, pelos índices autobiográficos que nela se apresentam, permite uma leitura autoficcional. "Dulce", no conto, é autora, narradora e personagem - e é a cadela Jinja, na qual se metamorfoseia e com a qual divide, pois, espaço de narração. "Dulce" e "Jinja" identificam-se uma à outra e tiveram experiências semelhantes de marginalização. Em uma fala de Jinja, que fora animal de rua antes de ser adotada por uma amiga de Dulce, caberia muito bem a experiência pela qual passaram os retornados antes de sentirem algo próximo à integralização em Portugal: “A té essa altura não sabia o que era estar dentro do que quer que fosse. Quase tudo o que conhecia era por fora. Como Lisboa. Conhecia bem Lisboa por fora" (CARDOSO, 2017, p. 115).

Neste artigo, foi feita, então, uma breve leitura desses recursos narrativos no conto “Tudo são histórias de amor", entendendo-o como exemplo de uma narrativa pós-moderna 
L. F. Silva Metamorfoses: deslocamento e pertencimento em "Tudo são histórias de amor", de Dulce Maria Cardoso

cujo sujeito que narra é um sujeito fragmentado, deslocado e descentralizado (HUTCHEON, 1991; SAID, 2004; HALL, 2006). A narradora, sendo uma "voz de muitas vozes", e identificando-se à própria Dulce Cardoso autora, identifica-se, ainda, a uma ex-cadela de rua, em um movimento metamórfico, polifônico, simbólico e autoficcional.

\section{Metamorfoses:}

\subsection{Jinja e Dulce (Maria Cardoso)}

Em um mise en abyme, "Metamorfoses" é nome de um texto que a narradorapersonagem de "Tudo são histórias de amor" está compondo sobre Lisboa, processo que vamos acompanhando. A narrativa dentro da narrativa ganha esse título devido às transformações pelas quais a capital portuguesa passou ao longo dos séculos, referenciadas no texto. Este, por sua parte, recomeçado e reescrito constantemente, como se a narradora estivesse se decidindo sobre como abordar seu tema, metamorfoseia-se ele e nele mesmo. Em um terceiro movimento metamórfico, que é o tratado nesta seção, a narradorapersonagem começa por nos explicar que está, naquele momento, transformada em Jinja, uma cadela rafeira que morrera havia um mês. O contrário, porém, talvez seja mais adequado: Jinja transformara-se em Dulce, nome da narradora, ao "entrar na cabeça" dela: “[...] estou a escrever um texto sobre Lisboa porque entrei na cabeça de Dulce" (CARDOSO, 2017, p. 112). Isso acontece, justamente, quando esta experimentava suas ideias:

Foi a Ana, uma amiga comum, que avisou a Dulce através do chat do gmail: a Jinja morreu, a nossa Jinja morreu. A notícia da minha morte no canto inferior direito do ecrã do computador, como um aparte no texto Metamorfoses. Metamorfoses. Umas mais incompreensíveis do que outras. Umas mais inúteis do que outras (CARDOSO, 2017, p. 116).

Jinja pertencia a uma amiga de Dulce chamada João. Jinja, ex-cadela de rua, deslocada, morando nos arredores de Lisboa, afirma ter feito do coração de João o seu lar (CARDOSO, 2017), após contar: 
L. F. Silva Metamorfoses: deslocamento e pertencimento em "Tudo são histórias de amor", de Dulce Maria Cardoso

[...] Amei muito a João. Foi a João que me descobriu errante num baldio perto de sua casa. Durante semanas, a João e eu avistávamo-nos, ainda que não nos aproximássemos uma da outra. Trazia-me comida, só que o medo era em mim maior do que a terrível fome. Já aprendera, com os anos que levava de rua, que os maiores perigos vinham muitas vezes mascarados de generosidade. Eu era uma cadela prevenida. A João afastava-se para que eu comesse e ficava a vigiar-me, lá longe, escondida pelos carros. Mal eu farejava comida, a fome crescia ainda mais e tornava-se impossível resistir. Ela esperava que eu terminasse a comida. Não demorava muito, eu era uma cadela sôfrega. Nunca deixei de o ser, a memória da fome nunca se esquece (CARDOSO, 2017, p. 114).

A desconfiança de Jinja perante o mundo é consciência da hostilidade sofrida por aquele que é considerado o diferente, o Outro. Ao mesmo tempo, é uma situação defensiva e, por vezes, também hostil. Dentro da comparação que vem sendo feita, aqui, entre as vozes narrativas do conto e o lugar do exilado, é possível lembrar de Said (2003) quando ele aponta:

O exílio é uma condição ciumenta. $\mathrm{O}$ que você consegue é exatamente o que você não tem vontade de compartilhar, e é ao traçar linhas ao seu redor e ao redor de seus compatriotas que os aspectos menos atraentes de estar no exílio emergem: um sentimento exagerado de solidariedade de grupo e uma hostilidade exaltada em relação aos de fora do grupo, mesmo aqueles que podem, na verdade, estar na mesma situação que você (SAID, 2003, p. $51)$.

Assim, pensando nesse lugar em que se encontrava, o do abandono e da autodefesa, a cadela reflete também sobre aquele em que se encontra no momento: a cabeça de Dulce. E diz:

[...] não é fácil vingar cá dentro [da cabeça de Dulce]. Nada fácil. A função principal do pensamento dominante - o de fora e o de dentro - é exactamente a de exercer esse domínio: se quase nada se sabe sobre o que é semelhante, como se pode saber sobre o que é diferente? Se não se pode saber e entender o que é diferente, como se pode aceitá-lo? O mundo que existe na cabeça de um é muito diferente do que existe na cabeça de outro. E ambos muito diferentes - diferenças assustadoras - do mundo que existe fora de nós, esse mundo que nos chega coado pelos sentidos. Não se sabe o que os sentidos de uns e de outros sentem nem como sentem, e por isso não podemos mais do que pressentir-nos (CARDOSO, 2017, p. 117). 
L. F. Silva Metamorfoses: deslocamento e pertencimento em "Tudo são histórias de amor", de Dulce Maria Cardoso

Ao longo do conto, vamos sabendo, dentre os fragmentos do texto "Metamorfoses", um pouco mais sobre o que pensa Jinja-Dulce. Por fim, Dulce não apenas retoma seu lugar como narradora-personagem como passa, também, a se associar à autora Dulce Maria Cardoso em um movimento autoficcional, entendendo "autoficção" segundo Anna Faedrich em “Autoficção: um percurso teórico":

[...] prática literária contemporânea de ficcionalização de si, em que o

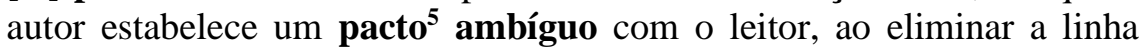
divisória entre fato/ficção, verdade/mentira, real/imaginário, vida/obra, etc; o tempo presente da narrativa e o modo composicional da autoficção, que é caracterizado pela fragmentação, uma vez que o autor não pretende dar conta da história linear e total de sua vida; o movimento da autoficção, que é da obra de arte para a vida - e não da vida para a obra, como na autobiografia -, potencializando o texto enquanto linguagem criadora; identidade onomástica entre autor, narrador e protagonista, que pode ser explícita ou implícita, desde que exista o jogo da contradição, criado intencionalmente pelo autor no próprio livro. E, por fim, a palavra-chave que marca a autoficção como um gênero híbrido: a indecidibilidade (FAEDRICH, 2016, p. 44-45, grifos da autora).

Essa metamorfose de Jinja (narradora-personagem) outra vez em Dulce (narradorapersonagem), simultânea à metamorfose de Dulce (narradora-personagem) em Dulce Maria Cardoso (autora-narradora-personagem), ocorre, primeiro, em um parágrafo repleto de índices autobiográficos. São vestígios dessa escritora que é, também, retornada:

Amanhecia quando vi Lisboa pela primeira vez. Foi na véspera de fazer onze anos. Contrariamente a Ulisses e aos romanos, não me apaixonei logo pela cidade. É preciso estarmos disponíveis para nos apaixonarmos, e eu cheguei fugida de uma guerra civil, fugida de um lugar a que julgava pertencer: Luanda. Para além disso, falava de uma maneira diferente do

\footnotetext{
${ }^{5}$ Referência a'O pacto autobiográfico (2008) de Philippe Lejeune. Nesse livro, o teórico francês propõe uma definição para autobiografia em que um dos pressupostos é a correspondência nominal entre autor, narrador e personagem em uma obra (pacto autobiográfico). Partindo desta e de outras características que propõe para a autobiografia, ele monta uma tabela por meio da qual demonstra as diferenças entre autobiografia e romance. Como, porém, não consegue, naquele momento, encontrar uma definição satisfatória para uma obra que tivesse teor romanesco e, ainda assim, contivesse o pacto autobiográfico, deixa incompleta essa "casa" da tabela. Até a publicação de Fils, de Serge Doubrovsky: "Em seu 'romance' Fils, Serge Doubrovsky dará a seu personagem seu próprio nome. Essa ambiguidade do contrato de leitura traduz a ambiguidade de seu projeto: veracidade da informação, liberdade de escrita. [...] Fils é batizado 'autoficção'. A palavra não serve de subtítulo genérico (a indicação será 'romance'), mas é proposta na quarta capa do livro [...]”' (LEJEUNE, 2014, p. 23). É depois da publicação de Fils que o termo "autoficção" será reconceituado várias vezes por Doubrovsky e outros teóricos da área.
} 
L. F. Silva Metamorfoses: deslocamento e pertencimento em "Tudo são histórias de amor", de Dulce Maria Cardoso

que aqui se falava, tinha um aspecto diferente do que aqui se usava. Demorou muito tempo a haver sequer vontade de entendimento. Por tudo isto ou por nada disto - tanto faz - a paixão por Lisboa demorou a acontecer. Lisboa não se importou e esperou por mim (CARDOSO, 2017, p. 126).

Em um segundo momento, há a correspondência nominal entre aquela que narra, aquela que é personagem e aquela que é autora - e que se permitiu, até ali, ser Jinja: "No dia 8 de Outubro de 2013 não morri. Rafeira, porte pequeno, cabelo pintado, quase dourado, olhos míopes de uma cor indefinida que muda consoante a luz que lhes bate. Guardo a Jinja comigo. Chamo-me Dulce" (CARDOSO, 2017, p. 126).

\subsection{Metamorfoses: Lisboa como texto}

Entre o momento em que Jinja aparece como narradora-personagem até o momento da fusão entre Jinja, Dulce e Dulce Maria Cardoso, temos inúmeros fragmentos relacionados ao texto que a narradora - composta, afinal, por essas três figuras - está tentando escrever.

O texto, chamado "Metamorfoses", entrecruza-se à narrativa principal na medida em que o que a narradora narra parte de reflexões sobre aquilo que está escrevendo nesse "texto dentro do texto".

O primeiro fragmento é uma releitura do mito de que o Ulisses ${ }^{6}$ da Odisseia homérica teria fundado Lisboa.

Esse mito, que nasce na literatura latina (GUERRA, 2020) e aparece em obras de inúmeros autores portugueses, incluindo Camões e Pessoa, ganha amplitude no Renascimento. Rogério Miguel Puga (2011), em “A odisseia de um mito: diálogos intertextuais em torno da fundação de Lisboa por Ulisses nas literaturas anglófonas", escreve:

\footnotetext{
${ }^{6}$ É interessante notar que, ainda que nas epopeias homéricas Ulisses tenha sido um rei, um guerreiro e um saqueador de cidades, ele também dá vestígios de colonizador. Esse detalhe é observado por Bernard Knox (2011) em sua introdução à obra, a partir do episódio da chegada de Ulisses à terra dos ciclopes, no canto IX: "É que os Ciclopes não têm naus de vermelho pintadas / nem têm no seu meio homens construtores de naus, / [...] naus que dessem / conta das suas necessidades, / chegando às cidades dos homens, [...] / homens esses que teriam feito da ilha um terreno cultivado, / pois a terra não é má: tudo daria na época própria. / Há prados junto às margens do mar cinzento, / bem irrigados e amenos, onde as vinhas seriam imperecíveis. / A terra é fácil de arar; e na altura certa poder-se-ia ceifar / excelentes colheitas, de tal forma rico é o solo por baixo" (HOMERO, 2011, p. 261). Esse trecho, aliás, lembra ao leitor brasileiro a Carta de Pero Vaz de Caminha.
} 
L. F. Silva Metamorfoses: deslocamento e pertencimento em "Tudo são histórias de amor", de Dulce Maria Cardoso

Como recorda Maria de Fátima Rambaud, os autores renascentistas recuperam a lenda para reforçar as glórias marítimas lusas, enquanto a semelhança fonética entre o nome latino de Ulisses e o topónimo Olisipo fortalece essa convicção [...]. Recordemos, a propósito dessa utilização do mito nas literaturas portuguesa e anglófonas, a forma como os autores criam a sua própria mitopoética ao combinar elementos da mitologia antiga com as suas próprias criações literárias para rentabilizar uma elaborada rede de simbologias que tem como ponto de partida mitos e vivências da Antiguidade Clássica textualizados ao longo dos séculos (PUGA, 2011, p. 148-149).

A utilização desse mito também se justifica, de acordo com Amílcar Guerra (2020) em “Questões míticas, literárias, toponímicas e étnicas da Lisboa pré-romana”, pelo

[...] princípio que preside à historiografia de período moderno ou contemporâneo, muitas vezes mais preocupada em dignificar as suas origens, associando-lhes algo de particularmente notável. Em geral, escolhe-se um fundador sublime em volta do qual se elabora uma narrativa que torna mais notável, como se uma cidade tivesse necessidade de demonstrar que a sua dignidade atual se encontra na razão direta da nobreza que tivera já por nascimento (GUERRA, 2020, p. 100).

Guerra complementa dizendo que Lisboa "[...] distingue-se pela cronologia bastante precoce em que surge a explicação histórica da sua criação, a qual se deve simultaneamente o facto de ser uma cidade bem conhecida e apresentar uma fonética propícia ao desenvolvimento desse modelo explicativo tradicional" (GUERRA, 2020, p. 102), isto é, o remoto nome "Olisipo" da atual Lisboa. Mesmo aqui, porém, como reforça Guerra, tratamse de pseudo-etimologias para esse nome, associando Olisipo a Ulisses/Ulisseia. "Ulisses", afinal, como também aponta o teórico, é o nome latinizado do herói grego "Odisseu”.

Em resumo, Ulisses como um "fundador sublime” (GUERRA, 2020) de Lisboa faz parte do imaginário cultural português. No poema "Primeiro/Ulysses" (em Mensagem), Fernando Pessoa escreve:

Este, que aqui aportou,

Foi por não ser existindo.

Sem existir nos bastou.

Por não ter vindo foi vindo

E nos creou (PESSOA, 2016, p. 20). 
L. F. Silva Metamorfoses: deslocamento e pertencimento em "Tudo são histórias de amor", de Dulce Maria Cardoso

Segundo uma das variações mais antigas da lenda, Olisipo teria sido a ilha da deusa Calipso, na qual o herói homérico atrasa por mais sete anos sua viagem de retorno a Ítaca. Em outra versão, bastante recente e apontada por Puga, Calipso teria dado origem às sete famosas colinas lisboanas:

\begin{abstract}
A fusão de tradições literárias marca também presença num recente guia de viagem literário e cultural sobre Lisboa. Nessa obra publicada em 2003 Paul Buck sumaria a lenda na secção dedicada à história da urbe, ou seja, Ulisses inaugura muitos dos textos sobre a capital lusa, e nesta versão Calipso dá origem às sete colinas de Lisboa: "Legend suggests that Lisbon identifies Ulysses as its founding father, strangely adding that it was even here that the sea nymph Calypso fell in love with him, turning herself into a snake whose coils formed the seven hills. Perhaps the myth has more to do with a similarity to the place's later name, Olissipo" (PUGA, 2011, p. 168).
\end{abstract}

Dulce Cardoso, em sua releitura do mito, segue essa ideia de que as colinas teriam sido criadas à época de Ulisses, mas, ao invés de atribuir o feito a Calipso, associa-o a uma criatura mítica chamada Ophiusa. Ophiussa, "terra das serpentes", é o nome que, supostamente, os gregos davam ao território que hoje é Lisboa.

A Ophiusa de Cardoso, metade humana e metade serpente, teria dado origem às sete colinas quando Ulisses voltou para Penélope:

[...] Ainda não tinha Ulisses chegado ao mar e já Ophiusa dera pela sua ausência, fazendo ouvir-se por todo o lado gritos de desespero mais altos e ameaçadores do que qualquer trovão. Como nunca nada se pode interpor entre um homem e o seu destino, fez-se Ulisses ao mar no preciso momento em que Ophiusa jurava aos deuses trazê-lo de volta, se vivo para o amar, se morto para o adorar. Arrastou Ophiusa o seu enorme e destruidor corpo de serpente em direcção às águas e, aí chegada, vendo Ulisses já fora do seu alcance, contorceu tão violentamente e com tanta dor o seu corpo que sete colinas surgiram no lugar raso em que havia existido Ulisseia (CARDOSO, 2017, p. 127).

As sete colinas também aparecem em uma reflexão da narradora após outro fragmento - ou melhor, outra metamorfose de seu texto "Metamorfoses": "[...] São Jorge, São Vicente, Santo André, Santa Catarina, São Roque, Sant'Ana, Chagas. Lisboa tremeu como nunca nenhuma outra cidade tremeu, nem antes nem depois. Lisboa tremeu, o seu corpo feriu-se mas as suas sete colinas mantiveram-se de pé” (CARDOSO, 2017, p. 120). A 
L. F. Silva Metamorfoses: deslocamento e pertencimento em “Tudo são histórias de amor", de Dulce Maria Cardoso

narradora se refere ao episódio do terremoto de 1755, que em "Metamorfoses" aparece como crônica. Esse fragmento de crônica, porém, ao invés de reforçar os discursos históricos oficiais, é irônico ao frisar que, no momento da tragédia, “[...] rezava o povo nas muitas igrejas erguidas com o dinheiro do ouro e especiarias vindos do Império" (CARDOSO, 2017, p. 18). Por outro lado, essa menção também é referência à noção moralista, defendida por muitos autores, de que o terremoto teria sido consequência de um castigo divino. Como escreve Ricardo Hiroyuki Shibata (2018) em “Uma cidade e tantos vícios. Imagem de Lisboa à época das navegações portuguesas":

O tema da cidade e seus correlatos sempre foi mote constante da história e da literatura durante os séculos. A narrativa bíblica da destruição de Sodoma e Gomorra pode muito bem dar o lance inicial. Segundo diz o Antigo Testamento, no capítulo 18 do Genesis, Deus havia aniquilado as duas cidades, em que grassavam a imoralidade (soberba, maldade, desprezo pelos pobres) e a perversão sexual, por fogo e enxofre que se precipitaram dos céus. Para Homero, o resultado do embate entre gregos e troianos foi, antes de tudo, a vitória da astúcia sobre a iniquidade. [...] $\mathrm{Na}$ Idade Média, as cidades sofreram as mazelas da peste, que surgiu em resposta imediata aos pecados dos homens. E um pouco mais adiante, no século XVII, a cidade de Port Royal, um porto que centralizava as rotas de comércio setentrional do Atlântico, afundou completamente no mar do Caribe por conta de um terremoto em 1692. Considerada a cidade mais rica do mundo à época, era também a mais pervertida ("wickedest city"). Antes, porém, no século XVI, em Portugal, para muitos escritores, havia a expectativa da destruição de Lisboa. Mesmo porque se a riqueza e o esplendor de uma cidade trazia consigo correlativamente a iminência de sua derrocada por meio da destruição e da ruína total, a qualquer momento, Lisboa haveria de passar por alguma catástrofe terrível e, com isso, acabaria o sonho de um império português à escala transatlântica (SHIBATA, 2018, p. 217-218).

A narradora de "Tudo são histórias de amor", refletindo sobre o próprio trecho de "Metamorfoses" que acabara de escrever, coloca:

Ninguém ousa compreender o que é tão tragicamente incompreensível. Kant, Voltaire, Rousseau, Goethe e outros fazedores do pensamento que nos enforma reflectiram sobre o terramoto de Lisboa. Castigo de um deus irónico que salvou os que pecavam nos bordéis em vez de poupar os que oravam nas

igrejas, exibição de um deus cruel que não escolhe quem ceifa, ou tãosomente uma nefasta conjugação de causas naturais que a ciência levaria séculos a explicar completamente? Culpa e expiação ou mero acaso? Veio 
L. F. Silva Metamorfoses: deslocamento e pertencimento em "Tudo são histórias de amor", de Dulce Maria Cardoso

a Razão e o Iluminismo, e o mundo avançou, como por certo estava destinado (CARDOSO, 2017, p. 119).

Quando aponta os "fazedores de pensamento", a narradora se coloca fora da tradição humanista liberal, ou seja, identifica-se com as margens teorizadas por Hutcheon (1991):

[O pós-modernismo] questiona as próprias bases de qualquer certeza (história, subjetividade, referência) e de quaisquer padrões de julgamento. Quem os estabelece? Quando? Onde? Por quê? O pós-modernismo assinala menos uma "desintegração" ou uma "decadência" negativa da ordem e da coerência (KaWer 1968) do que um desafio ao próprio conceito em que nos baseamos para julgar a ordem e a coerência (HUTCHEON, 1991, p 84).

A narradora é marginal porque é deslocada: abandonada e periférica quando está na figura de Jinja, e retornada (refugiada/exilada) quando se identifica à Dulce Maria Cardoso ao final do conto. A narradora é marginal, também, porque é uma voz feminina. Em um dos eixos narrativos de "Metamorfoses", aliás, acompanhamos a história de uma lisboana de meia-idade recém-deixada pelo marido, o que nos faz retomar tanto as Penélope, Circe e Calipso homéricas quanto a Ophiusa de Cardoso. Aqui podemos também fazer um importante contraponto entre essas heroínas e Ulisses. Em "A jornada do herói e da heroína: uma discussão analógica à luz da mitopsicocrítica", Ana Maria Leal Cardoso e Maria Goretti Ribeiro (2018) buscam, a partir do modelo do herói mítico de Joseph Campbell e das teorias junguianas acerca do Ego, entender como, em contrapartida, funciona a jornada da heroína nas narrativas, especialmente após as contribuições dos movimentos feministas à teoria literária. Para isso, as autoras apoiam-se nas formulações de Nelly Novais Coelho, Ellen Douglas, Carol Christ e Annis Pratt e apontam aspectos como: narrativas sob o ponto de vista da mulher mudando o teor dos enredos; superação da condição de vítima das protagonistas; rompimento das dicotomias limitadoras ligadas à mulher, que sempre a colocava em relação ao homem. Após trazerem a conclusão de que, na jornada heroica em $s i$, há semelhanças entre o herói e a heroína jovem (ainda que cada um com seus objetivos), Cardoso e Ribeiro (2018) apontam que a trajetória da heroína jovem e da heroína madura tem algumas diferenças:

Entendemos que a heroína feminista representada na literatura escrita por mulheres é fruto de um longo processo histórico de evolução do 
L. F. Silva Metamorfoses: deslocamento e pertencimento em "Tudo são histórias de amor", de Dulce Maria Cardoso

pensamento e de revolução das ideias e resulta da atuação do sujeito feminino como articulador da palavra escrita. Vendo sob este prisma, a jornada da heroína requisita um modelo híbrido porque a busca social da mulher jovem, que deseja adquirir identidade social difere da busca da mulher madura na sua jornada de renascimento, esta que realiza uma viagem interior em busca de crescimento psíquico. Para tanto o modelo da trajetória da mulher madura pontua, com indisfarçável relevância, a morte psicológica como ato simbólico desencadeador desta etapa natural da vida e meio promotor de renascimento. Isto porque a trajetória da heroína madura nas narrativas escritas por mulheres, de preferência maduras também, tende à autobiografia e à escrita de si. Temos comprovado que sua principal intenção é a catarse dos dramas existenciais a fim de curar feridas psíquicas abertas por longo tempo (CARDOSO; RIBEIRO, 2018, p. 71).

A mulher madura que aparece no fragmento de "Metamorfoses" precisa, de fato, renascer após o marido ter ido embora, trocando-a por uma mulher mais jovem. Ela está refletindo sobre isso quando vai amanhecendo em Lisboa, e é logo após esse fragmento que vem o já demonstrado trecho com índices autobiográficos de Dulce Maria Cardoso, cujo início, sincronizado com o "Metamorfoses", é: “Amanhecia quando vi Lisboa pela primeira vez" (CARDOSO, 2017, p. 126). Assim, também a narradora de "Tudo são histórias de amor", identificada com todas as personagens femininas sobre as quais escreveu, assume uma escrita de si para curar uma ferida psíquica: o não lugar/não estar (TOLENTINO, 2017) de uma retornada escrevendo sobre Lisboa, e que demorou a fazer desta a sua casa (CARDOSO, 2017).

\section{Considerações finais}

Conforme proposto, foi feita, neste artigo, uma leitura do conto "Tudo são histórias de amor" a partir de suas múltiplas camadas textuais, entendendo-as como partes do processo de construção do sujeito que narra. Como se demonstrou, o texto "Metamorfoses", construído e reconstruído dentro do enredo de "Tudo são histórias de amor", faz referência às metamorfoses da narradora, de Lisboa e do próprio texto. Aquela, que começa identificada com a cadela Jinja - "Chamo-me Jinja" (CARDOSO, 2017, p. 111) -, que teria "entrado na cabeça" de Dulce quando esta escrevia um texto sobre a capital portuguesa, volta, ao final, a ser Dulce, e Dulce se identifica à própria autora Dulce Maria Cardoso. A escritora Dulce 
L. F. Silva Metamorfoses: deslocamento e pertencimento em "Tudo são histórias de amor", de Dulce Maria Cardoso

Cardoso, pelo local que ocupa na sociedade e na literatura portuguesa, insere-se no texto como retornada - que, por sua vez, é, ou ao menos foi, um não-lugar. Essa condição define a temática do enredo principal e a forma e enredos do "Metamorfoses", que vão sendo construídos junto ao sujeito que narra.

Assim, apontou-se “Tudo são histórias de amor” como uma narrativa pós-moderna, lembrando de Hutcheon (1992) quando declara que "O pós-modernismo não leva o marginal para o centro. Menos do que inverter a valorização dos centros para a das periferias e das fronteiras, ele utiliza esse posicionamento duplo paradoxal para criticar o interior a partir do exterior e do próprio interior" (HUTCHEON, 1992, p. 98). A narradora de "Tudo são histórias de amor", pela identificação com a ex-cadela abandonada, com as personagens femininas que cria e com a própria Dulce Maria Cardoso, foi descrita, neste trabalho, como voz de um sujeito fragmentado, deslocado e descentralizado (HUTCHEON, 1991; SAID, 2004; HALL, 2006).

O conto funcionou como um acerto de contas com Lisboa simultâneo a uma declaração de amor à cidade, ressignificando-a; da mesma forma como Jinja custou a aceitar o amor da João, passando depois a pertencer a ela, Dulce Maria Cardoso, segundo o que narra, demorou a sentir-se parte da capital portuguesa. E o sentimento de pertencimento vem junto à aceitação da própria personalidade fragmentada inerente a todo sujeito que, de algum modo, viveu o exílio. Dessa maneira, em um processo metamórfico, simbólico, polifônico e autoficcional, a narradora de "Tudo são histórias de amor" nos dá uma dimensão das “dimensões simultâneas” (SAID, 2003, p. 59) que experencia.

\section{Referências:}


L. F. Silva Metamorfoses: deslocamento e pertencimento em "Tudo são histórias de amor", de Dulce Maria Cardoso

CARDOSO, Ana Maria Leal; RIBEIRO, Maria Goretti. A jornada do herói e da heroína: uma discussão analógica à luz da mitopsicocrítica. In: Téssera, Uberlândia, v.1, n.1, p.5874, 2018.

CARDOSO, Dulce Maria. Tudo são histórias de amor. In: CARDOSO, Dulce Maria. Tudo são histórias de amor. Rio de Janeiro: Tinta-da-china Brasil, 2017

FAEDRICH, Anna. Autoficção: um percurso teórico. Criação \& Crítica, n. 17, p. 30-46, 2016.

FIGUEIREDO, Isabela. Caderno de memórias coloniais. São Paulo: Todavia, 2018.

GUERRA, Amílcar. Questões míticas, literárias, toponímicas e étnicas da Lisboa préromana. In: Amílcar Guerra, Maria Conceição Freitas, \& Mário Cachão (Eds.). Lisboa romana, Felicitas Iulia Olisipo: território e memória. Caleidoscópio: Casal de Cambra, 2020.

HALL, Stuart. A identidade cultural na pós-modernidade. Tradução de Tomaz Tadeu da Silva e Guacira Lopes Louro. 11 ed. Rio de Janeiro: DP\&A editora, 2006.

HOMERO. Odisseia. Tradução de Frederico Lourenço. São Paulo: Penguin Classics Companhia das Letras, 2011.

HUTCHEON, Linda. "Descentralizando o pós-moderno: o ex-cêntrico". In: HUTCHEON, Linda. Poética do pós-modernismo: história, teoria, ficção. Tradução de Ricardo Cruz. Rio de Janeiro: Imago Ed., 1991.

KNOX, Bernard. Introdução. In: HOMERO. Odisseia. Tradução de Frederico Lourenço. São Paulo: Penguin Classics Companhia das Letras, 2011, p. 7-93.

LEJEUNE, Philippe. "O pacto autobiográfico". In: LEJEUNE, Philippe. O pacto autobiográfico; de Rousseau à Internet. Belo Horizonte: Ed. UFMG, 2008, p. 13-47.

Autoficções \& Cia. In: NORONHA, Jovita Maria Gerheim (Org.). Ensaios sobre a autoficção. Tradução de Jovita Maria Gerheim Noronha e Maria Inês Coimbra Guedes. Belo Horizonte: Editora UFMG, 2014, p. 21-37.

PESSOA, Fernando. Primeiro/Ulysses. In: PESSOA, Fernando. Mensagem. Obra poética de Fernando Pessoa - volume 1. Rio de Janeiro: Editora Nova Fronteira, 2016, p. 20.

PUGA, Rogério Miguel. A odisseia de um mito: diálogos intertextuais em torno da fundação de Lisboa por Ulisses nas literaturas anglófonas. Ágora Estudos Clássicos em Debate, Aveiro, n. 13, p. 145-175, 2011. 
L. F. Silva Metamorfoses: deslocamento e pertencimento em "Tudo são histórias de amor", de Dulce Maria Cardoso

SAID, Edward. Reflexões sobre o exílio. In: SAID, Edward. Reflexões sobre o exílio e outros ensaios. São Paulo: Companhia das Letras, 2003. p.46-60.

SANTOS, Boaventura de Sousa. Entre Próspero e Caliban - colonialismo, pós-colonialismo e interidentidade. Novos estudos CEBRAP, n. 66, p. 23-52, 2003.

SHIBATA, Ricardo Hiroyuki. Uma cidade e tantos vícios. imagem de Lisboa à época das navegações portuguesas. Revista Philologus, Rio de Janeiro, ano 24, n. 72, p. 217-232, 2018. TOLENTINO, Eliana da Conceição. Retorno e retornados - um não lugar, um não estar. In: XV Congresso Internacional da ABRALIC - textualidades contemporâneas, 2017, Rio de Janeiro. Anais eletrônicos do XV Congresso Internacional da ABRALIC - textualidades contemporâneas, 2017. v. 4. p. 6049-6059.

Artigo recebido em: 19.05 .2021

Artigo aceito para publicar em: 08.07.2021 